\title{
EFFECT OF LAMINATE STIFFNESS ON FAILURE MODE IN FRP WRAPPED T BEAMS
}

\author{
S. K. Panigrahi ${ }^{1}$, A. Deb ${ }^{2}$, S. K. Bhattacharyya ${ }^{3}$ \\ ${ }^{1}$ Graduate Student, Department of Civil Engineering, Indian Institute of Technology Kharagpur, Kharagpur 721302, \\ India. \\ ${ }^{2}$ Associate Professor, Department of Civil Engineering, Indian Institute of Technology Kharagpur, Kharagpur \\ 721302, India \\ ${ }^{2}$ Director, Central Building Research Institute, Roorkee 247667, Uttarkhand, India \\ (Professor, Department of Civil Engineering, Indian Institute of Technology Kharagpur, Kharagpur 721302, India.)
}

\begin{abstract}
The effect of laminate modulus on crack pattern, mode of failure and strength of shear deficient Reinforced concrete T-beam wrapped with FRP laminate is studied. Specimens of $2.5 \mathrm{~m}$ span, designed to fail in shear, were tested for two point static loading. Displacements, strains, and crack pattern were monitored. The strength and mode of failure are found to depend on the crack pattern. Laminate modulus increase is found to result in reduced web cracking and increased in web-flange junction cracking for $U$-wraps.
\end{abstract}

Keywords: Fibre reinforced plastic (FRP). Reinforced concrete, T-beam. Laminate modulus

\section{INTRODUCTION}

The properties of the Fibre reinforced plastic laminate, in particular its stiffness and strength, are important in determining its effectiveness as a strengthening mechanism for reinforced concrete T-beams deficient in shear. Laminate stiffness can be enhanced by using either multiple layers of GFRP fabric with low to moderate elastic modulus, or by using a limited number of layers of AFRP or CFRP fabric with high elastic modulus. Increase in laminate stiffness may be expected to lead to higher failure loads for such beams, since stiffer laminates are likely to give rise to larger interfacial shear stresses resisting crack growth. However, Khalifa and Nanni (2000) report that the shear resistance may not increase proportionally with increase in the number of layers of FRP. According to the authors, there may exist a threshold thickness beyond which additional layers of FRP wrap may not be effective.

It is well known that the presence of FRP wraps gives rise to two additional failure modes that complicate strength prediction for such beams. These modes are FRP debonding and FRP rupture. FRP debonding is a process of apparent disintegration of the surface concrete underlying the bond. FRP rupture involves breakage of FRP fibers, starting from the most highly stressed region in the FRP and spreading rapidly to other parts of the FRP intersected by the main shear crack. Failure in T-beams, with externally applied FRP U-jackets reinforcing the web and soffit, can occur due to FRP rupture as well as due to interfacial debonding. Failure at the FRP-concrete interface due to the spread of debonding, governed by Mode II fracture, was extensively studied by Chen and Teng (2003a). As the primary shear crack widens, the shear stress in the interface adjacent to the discontinuity sharply increases, resulting in debonding. Lu et al. (2005) developed a bond-slip model for the concreteFRP interface encompassing both the hardening (prior to the initiation of debonding) and softening (progressive debonding) regimes. Other authors (Yuan et al. (2003), Teng et al. (2005)) have developed one-dimensional models that can describe the debonding process analytically. However the results obtained in this research indicate that the existence of a threshold laminate stiffness cannot be explained entirely in terms of debonding at the concreteFRP interface.

\subsection{Research Significance}

It is shown that increase in laminate modulus causes a sharp rise to shear stresses at web-flange junction in T-beams, thereby changing the mode of failure and adversely affecting load carrying capacity. Thus, failure at high laminate stiffness is seen to be driven by crack growth at the junction of beam and web rather than debonding in the web. It is also shown that the conventional assumption about the concrete contribution to the shearing resistance being independent of the FRP does not hold.

\section{EXPERIMENTAL STUDY}

Experiments were performed on eight reinforced concrete Tbeams. The experimental results were used to calibrate and validate the numerical models which were subsequently studied as part of a more detailed analysis.

\subsection{Experimental Specimens}

The specimens were of $2500 \mathrm{~mm}$ length and $225 \mathrm{~mm}$ effective depth (Fig. 1). The specimens did not have any 
stirrups in the shear span except two stirrups below the loading points and four stirrups below the support points to prevent localized failure. Thus the beams were shear deficient and designated as SO beams, the ' 0 ' indicating the absence of stirrups in the shear span. Two of the samples were not laminated $(0 \mathrm{~L})$, two were strengthened with a single layer (1L) of GFRP laminate of $0.62 \mathrm{~mm}$ thickness, two with five layers (5L) of GFRP laminate with thickness of $2.04 \mathrm{~mm}$ and two beams were strengthened with ten layers (10L) of GFRP laminate of $4.2 \mathrm{~mm}$ thickness. In all, four groups of beams i.e. S0-0L, S0-1L, S0-5L and S0-10L were tested, with the two specimens in each group being alike in all respects.

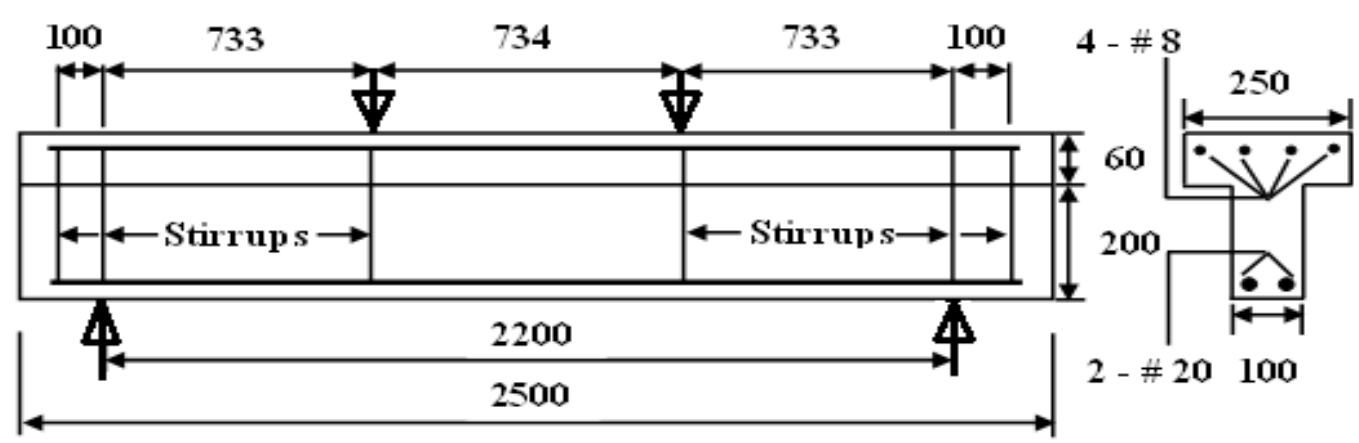

Fig. 1. Schematic diagram of S0-0L beam specimen (All units in mm)

Concrete with characteristic strength of $35 \mathrm{MPa}$ was used. The concrete mix ratio and water-to-cement ratio were 1: 1.9: 2.4 and 0.42 respectively. The Young's modulus and Poisson's ratio were $38 \mathrm{GPa}$ and 0.18 . The tensile strength found from split cylinder tests was $4 \mathrm{MPa}$. The reinforcement comprised $6 \mathrm{~mm}, 8 \mathrm{~mm}$ and $20 \mathrm{~mm}$ diameter high yield strength deformed (HYSD) bars of $500 \mathrm{MPa}$ yield strength (manufacturer's data). Unidirectional GFRP fabric, with $288 \mathrm{gsm}$ and $0.28 \mathrm{mmthickness,} \mathrm{was} \mathrm{used} \mathrm{for}$ strengthening. The GFRP laminate was applied continuously on the web and soffit of the T-beam along the shear span and had the form of a U-wrap. The laminate was bonded to the concrete using epoxy adhesive comprising Araldyte CY230 and hardener HY-951 in 9:1 ratio. The properties of the
1L, 5L and 10L laminates were determined (Table-1) by testing coupons of standard dimensions (ASTM ) in a Universal Testing machine (UTM).

The beams were loaded to failure under four point static loading at a loading rate of $1.2 \mathrm{~mm} /$ minute. LVDTs and dial gauges were used to measure the vertical displacements of the bottom surface of the beam at mid-span, at the shear span centers and at the load points. Electrical strain gauges were used to measure the strains in the longitudinal tensile steel near support, in the surface concrete at mid shear span and in the FRP laminate at web-flange junction. The strain gauge locations are given in Figs. 2-4.

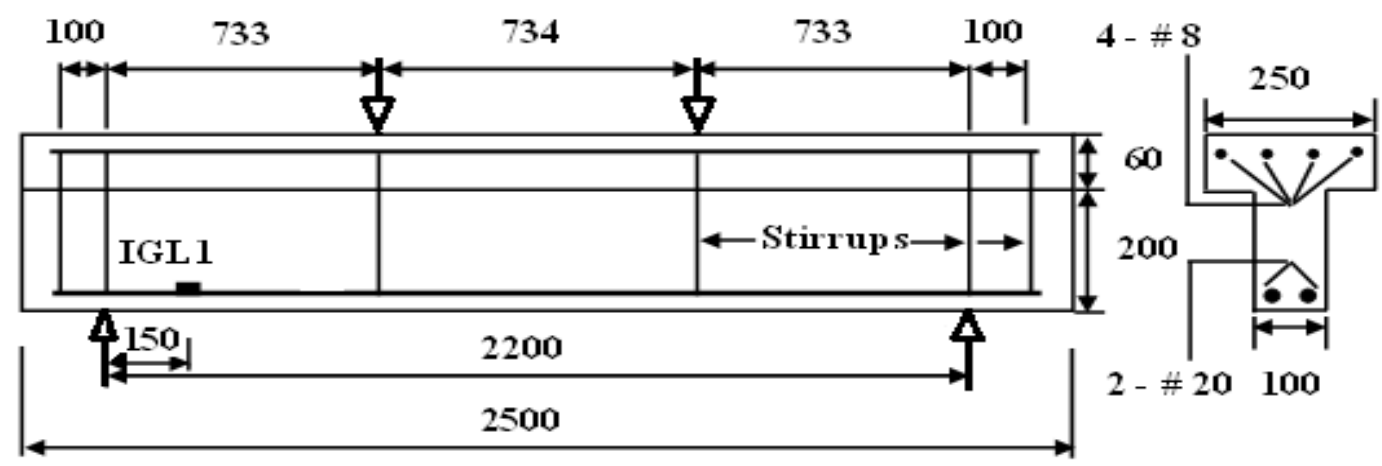

Fig 2 Strain gauge position on steel bar surface in S0 beams (All units in $\mathrm{mm}$ )

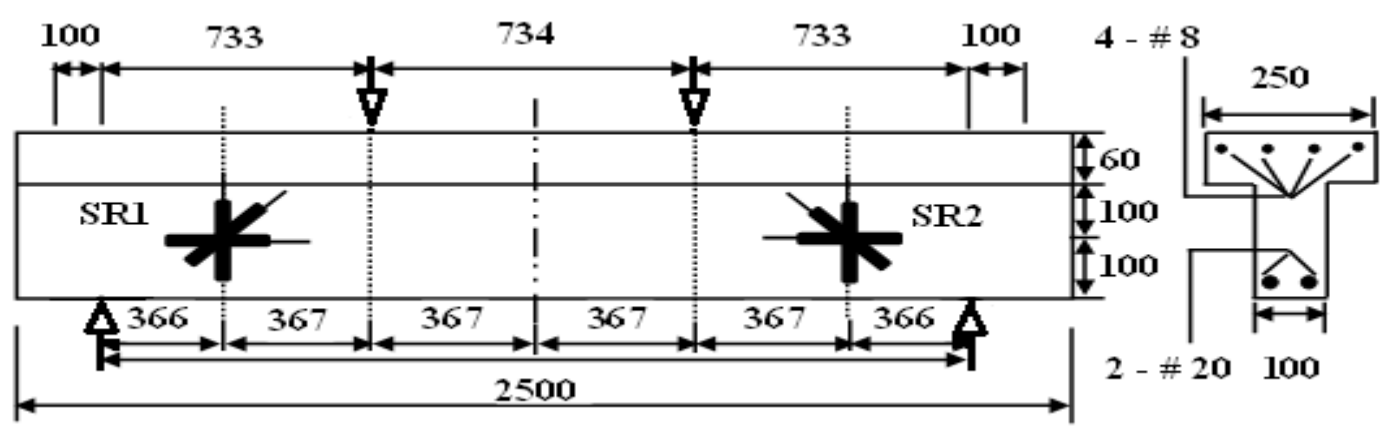

Fig. 3. Strain rosette position on concrete surface (All units in $\mathrm{mm}$ ) 


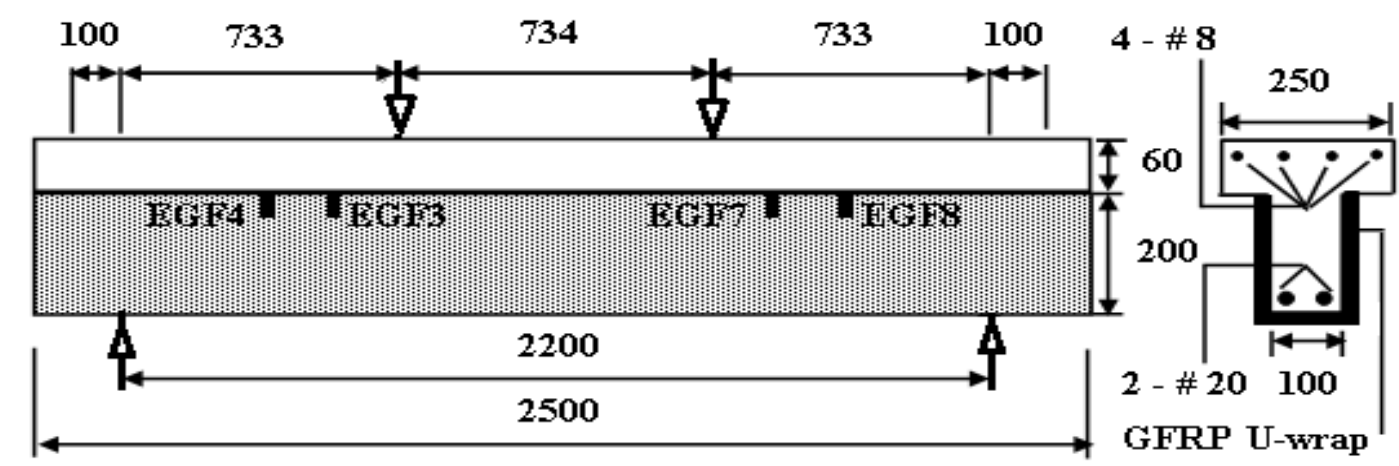

Fig.4. Gauge position on GFRP surface (All dimensions in $\mathrm{mm}$ )

\subsection{Equivalent Specimens with Higher Laminate}

\section{Modulus}

The modulus of the $1 \mathrm{~L}$ laminate was $18.7 \mathrm{GPa}$, while that for the 10L laminate was $23.8 \mathrm{GPa}$ (Table 1). The laminate modulus of FRP is known to widely. If the modulus of the $1 \mathrm{~L}$ laminate is denoted as $1 \mathrm{E}$, a review of the existing literature (e.g. Teng et al. (2001)) indicates that typical single layer GFRP laminates have laminate modulus values ranging between $1 \mathrm{E}$ to $3 \mathrm{E}$, single layer AFRP laminates have laminate modulus ranging between $3 \mathrm{E}$ to $5 \mathrm{E}$ and single layer CFRP laminates have laminate modulus ranging between $5 \mathrm{E}$ to $15 \mathrm{E}$ (Table 2).

Table 1: Laminate properties. The data for GFRP laminates of varying laminate thickness are from coupon tests. The data for AFRP and CFRP are from Teng et al. (2001).

\begin{tabular}{|c|c|c|c|c|c|c|c|c|c|}
\hline \multirow{2}{*}{$\begin{array}{l}\text { Type } \\
\text { of } \\
\text { Fabric }\end{array}$} & \multicolumn{2}{|c|}{$\begin{array}{l}\text { Laminate } \\
\text { thickness }(\mathrm{t})\end{array}$} & \multicolumn{2}{|l|}{$\mathrm{E}_{1}$} & \multirow[t]{2}{*}{$\begin{array}{l}K_{\text {laminate }} \\
\left(\mathrm{E}_{1} \times \mathrm{t}\right)\end{array}$} & \multirow{2}{*}{$\begin{array}{l}\mathrm{E}_{2} \\
\mathrm{MPa}\end{array}$} & \multirow[t]{2}{*}{$v_{12}$} & \multirow[t]{2}{*}{$\begin{array}{l}\mathrm{G}_{12} \\
\mathrm{MPa}\end{array}$} & \multirow{2}{*}{$\begin{array}{ll}\text { Long. } & \text { Tensile } \\
\text { strength } & \\
\mathrm{MPa} & \end{array}$} \\
\hline & $\mathrm{mm}$ & Type & $\mathrm{GPa}$ & Type & & & & & \\
\hline GFRP & 0.62 & $1 \mathrm{~L}$ & 18.7 & $1 \mathrm{E}$ & 1.00 & 233 & 0.377 & 6814 & 188.57 \\
\hline GFRP & 2.04 & $5 \mathrm{~L}$ & 23.9 & $1.28 \mathrm{E}$ & 4.21 & 1468 & 0.409 & 8504 & 301.00 \\
\hline GFRP & 4.20 & $10 \mathrm{~L}$ & 23.8 & $1.27 \mathrm{E}$ & 8.55 & 1893 & 0.411 & 8457 & 364.00 \\
\hline AFRP & 0.62 & $1 \mathrm{~L}$ & 95 & $5 \mathrm{E}$ & 5.00 & 1165 & 0.377 & 6814 & 950.00 \\
\hline CFRP & 0.62 & $1 \mathrm{~L}$ & 190 & $10 \mathrm{E}$ & 10.00 & 2330 & 0.377 & 6814 & 1890.0 \\
\hline
\end{tabular}

Table 2. Comparison between Experimental and Numerical response

\begin{tabular}{|c|c|c|c|c|c|c|c|c|c|c|c|}
\hline \multicolumn{6}{|c|}{ Experimental } & \multicolumn{6}{|l|}{ Numerical } \\
\hline \begin{tabular}{|l} 
Beam \\
Category
\end{tabular} & $\begin{array}{l}\mathrm{F}_{1} \\
\mathrm{kN}\end{array}$ & $\begin{array}{l}\mathrm{F}_{2} \\
\mathrm{kN}\end{array}$ & $\begin{array}{l}\mathrm{F}_{3} \\
\mathrm{kN}\end{array}$ & $\begin{array}{l}\Delta \\
(\mathrm{mm})\end{array}$ & $\begin{array}{l}\text { Mode } \\
\text { of failure }\end{array}$ & $\begin{array}{l}\text { Beam } \\
\text { Category }\end{array}$ & $\begin{array}{l}\mathrm{F}_{1} \\
\mathrm{kN}\end{array}$ & $\begin{array}{l}\mathrm{F}_{2} \\
\mathrm{kN}\end{array}$ & $\begin{array}{l}\mathrm{F}_{3} \\
\mathrm{kN}\end{array}$ & $\begin{array}{l}\Delta \\
(\mathrm{mm})\end{array}$ & $\begin{array}{l}\text { Mode } \\
\text { of failure }\end{array}$ \\
\hline S0-0L & 88 & 112 & - & 7 & Shear III & S0-0L & 96 & 123 & - & 8 & Shear III \\
\hline S0-1L & 89 & 163 & 148 & 9 & Shear II & S0-1L-1E & 99 & 198 & 189 & 12 & Shear II \\
\hline S0-5L & 91 & 178 & 160 & 9 & Shear III & S0-1L-5E & 96 & 190 & 193 & 11 & Shear III \\
\hline S0-10L & 118 & 180 & 168 & 9 & Shear III & S0-1L-10E & 121 & 181 & 185 & 10 & Shear III \\
\hline \multicolumn{12}{|c|}{ Nomenclature: } \\
\hline $\mathrm{F}_{1}$ & & \multicolumn{10}{|c|}{ Load at first crack } \\
\hline $\mathrm{F}_{2}$ & & \multicolumn{10}{|c|}{ Load at beam failure } \\
\hline $\mathrm{F} 3$ & & \multicolumn{10}{|c|}{ Load at bond failure } \\
\hline$\Delta$ & & \multicolumn{10}{|c|}{ Mid span deflection } \\
\hline Shear I & & \multicolumn{10}{|c|}{ Failure in shear, accompanied by FRP rupture } \\
\hline Shear II & & \multicolumn{10}{|c|}{ Failure in shear, preceded by bond failure between FRP and concrete } \\
\hline Shear III & & \multicolumn{10}{|c|}{ Failure in shear } \\
\hline
\end{tabular}

The shear strengthening effect of the laminate depends on the effective laminate stiffness $\left(K_{\text {laminate }}\right)$, defined as the product of the laminate modulus and laminate thickness. This can be seen from the one-dimensional model of Yuan et al. (2003). According to this model, prior to the onset of bond damage, the shear stress distribution along the bond is given by Eqn. (1), where $P$ is the shear load carried by the FRP laminate, $E_{p}, b_{p}, t_{p}$ and $E_{c}, b_{c}, t_{c}$ are the elastic modulus, 
width and thickness of the laminate and concrete respectively. $L$ is the length of the bond, and $x$ is the vertical distance along the bond length. It is clear from Eqn. (1), that the shear stress distribution at the interface depends on $E_{p} \times t_{p}$ i.e. on $K_{\text {laminate }}$.

$$
\tau=P\left[\frac{K_{\text {cohesive }}}{b_{p}^{2}}\left(\frac{1}{E_{p} t_{p}}+\frac{b_{p}}{b_{c} E_{c} t_{c}}\right)\right]^{0.5} \times \frac{\cosh \left[K_{\text {cohesive }} x^{2}\left(\frac{1}{E_{p} t_{p}}+\frac{b_{p}}{b_{c} E_{c} t_{c}}\right)\right]^{0.5}}{\sinh \left[K_{\text {cohesive }} L^{2}\left(\frac{1}{E_{p} t_{p}}+\frac{b_{p}}{b_{c} E_{c} t_{c}}\right)\right]^{0.5}}
$$

Table 1 shows laminate thickness and modulus values for the experimental beams, along with the corresponding values of $K_{\text {laminate }}$. In the experimental beams, the same fabric (with modulus $E$ ) was used in all cases while the laminate thickness was varied $(1 \mathrm{~L}, 5 \mathrm{~L}, 10 \mathrm{~L}$ etc.). Table 2 shows the $K_{\text {laminate }}$ values that would result if the laminate modulus were varied by changing the FRP fabric while maintaining a constant laminate thickness of $1 \mathrm{~L}$. It is clear that $K_{\text {laminate }}$ is close for the following combinations of thickness and modulus: (5L, 1L-5E) and (10L, 1L-10E). Hence, it is expected that the force-mid span displacement curves, crack patterns, failure modes and strains for the beam pair S0-5L and S0-1L-5E would be close, as would be the results for the beam pair S0-10L and S0-1L-10E.

This is verified using the finite element model described in the next Section. The finite element results for the S0-5L and S0-1L-5E pair of beams and the S0-10L and S0-1L-10E pair of beams are seen to be very close. In addition, the finite element results for the S0-5L and S0-10L beams are seen to compare very well with the experimental results.
Thus the finite element model enables meaningful study of the effect of laminate modulus on beam failure.

\subsection{The Finite Element Model and its Calibration}

The commercially available nonlinear finite element analysis code ABAQUS (Simulia, Inc., 2009) was used for the simulations. A quasi-static stress analysis is performed, using ABAQUS/Explicit, with the load applied sufficiently slowly to eliminate inertia effects.

The dimensions, loading and boundary conditions of the beams modelled were identical to the experimental specimens. In order to yield meaningful results, the mesh was refined sufficiently to yield convergent solutions. However the number of finite elements necessary to create a convergent model of the entire beam was found to be excessive. Hence instead of analysing the whole beam, symmetry conditions were used to create a convergent model of a quarter of the beam, as shown in Fig. 5.

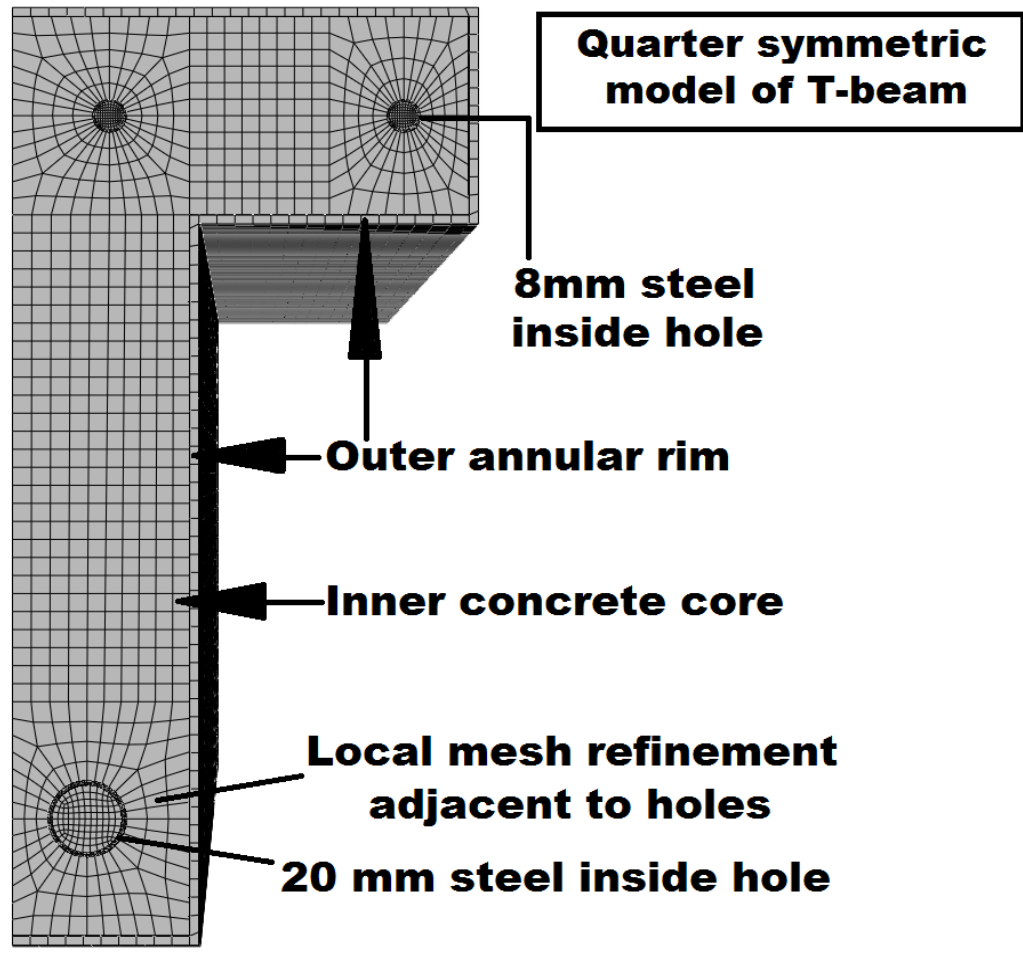

Fig. 5. Meshed section of T-beam 
The concrete in the T-beam was modelled using 8 noded reduced integration brick elements (C3D8R). The reinforcing steel was also modelled using C3D8R elements. The FRP laminate was modelled using 4 noded shell elements (S4R). The thin adhesive layer at the interface between FRP and concrete, comprising epoxy, was also modelled using S4R elements.

The concrete was modelled using a continuum damage mechanics based material model. Details of this material model are available in the ABAQUS v6.9 Analysis User's Manual. The concrete properties determined for the experimental specimens were used. ABAQUS requires the stress strain behaviour of the concrete in uniaxial compression as well as the stress-crack opening behaviour of the concrete in unaixial tension to be prescribed in the form of tabular data. Unconfined uniaxial compression tests were performed on concrete cylinders with a mix identical to that used for the experiments to get the stress-strain curve under uniaxial compression. The tensile strength of the concrete was obtained from split cylinder tests on cylinders with the same mix as used for the experiments. However in the absence of test data on the post peak portion of the tensile stress-crack opening curve the experimentally obtained tensile strength was used along with the empirical equations of Hordijk (1991) to generate the tensile stresscrack opening curve. This data, along with the uniaxial compression data obtained experimentally as described above, was then used in a finite element model of the S0 control beam. The applied load vs. mid-span displacement curve obtained from the simulation results was compared with the experimental load vs. mid-span displacement curve. Since there was significant mismatch, the tensile stress crack opening data was revised and the finite element simulation was rerun. This process was continued until a set of tensile stress vs. crack opening data could be arrived at which resulted in a good match between the simulation and experimental load-displacement curves. The resultant fracture energy of concrete was $70.50 \mathrm{~N} / \mathrm{m}$, which is a reasonable value for the grade of concrete considered. The calibrated force-mid span displacement curves along with the experimental one are shown in Fig. 6. The results are seen to match well. Steel was modelled as an elastic-plastic material with a Ramberg-Osgood (Ramberg and Osgood, 1943) type hardening law (with exponent $n=2$ ) and a yield strength of $500 \mathrm{MPa}$.

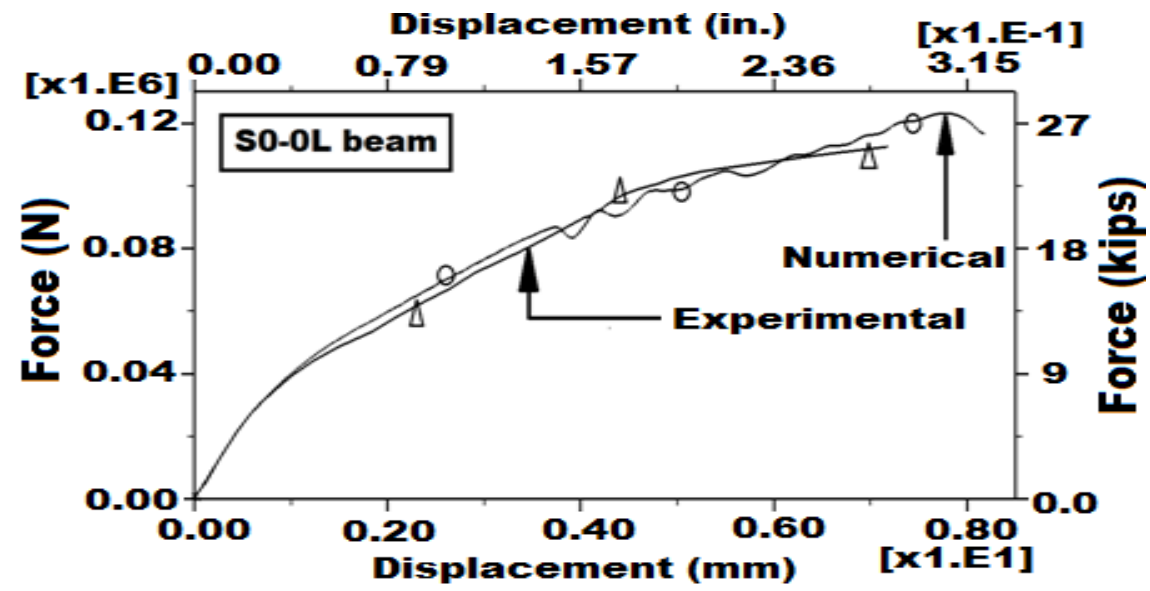

Fig.6. Calibrated force-mid span displacement curve of S0-0L beam

FRP composites were assumed to be a laminar with elastic properties defined by six material constants $E_{1}, E_{2}, G_{12}, G_{23}$, $G_{31}$ and $\mu_{12}$. These properties, for a single layer of laminate, were found by performing laboratory tests as described earlier. Since FRP is an elastic-brittle material, damage can initiate without plastic deformation. The damage initiation criteria adopted for FRP was based on Hashin's theory, with the fibres assumed to fail in tension only. Experimentally observed values of longitudinal tensile strength were used as damage initiation criterion for tensile fibre damage. Damage evolution in ABAQUS is based on energy dissipated during the damage process. To ensure brittle failure, the FRP material was assigned an extremely small value of fracture energy.

Epoxy was modelled as an elastic isotropic material. The density of epoxy was taken as $1900 \mathrm{~kg} / \mathrm{m}^{3}$. Poisson's ratio of epoxy was taken as 0.36 respectively. The Young's modulus of epoxy was taken as $4 \mathrm{E}+09 \mathrm{~N} / \mathrm{m}^{2}$ respectively.
For the numerical solutions presented here, all interfaces between concrete and steel were 'tied' to ensure perfect displacement compatibility using the ABAQUS tie constraint. However additional simulations were performed by implementing the bond-slip model proposed by Eligehausen et al. (1983) in an ABAQUS user-subroutine to model a compliant interface between concrete and steel. This was not found to materially affect the results. The interface between the outer surface of the T-beam web and the epoxy adhesive was modelled as a cohesive interface. The damage parameters for the concrete-GFRP interface were assigned the values obtained by Dai et.al. (2005). As in the present work, the grade of concrete used by Dai et al (2005) in their experiments had compressive strength of 35 $\mathrm{MPa}$. The GFRP used by the authors had an $E \times t$ (Young's Modulus $x$ thickness) value of $8.7 \mathrm{E}+3 \mathrm{~N} / \mathrm{mm}$. This value also compares reasonably well with the experimentally determined value of $E \times t$ for the GFRP used in the present simulations, which was $1.14 \mathrm{E}+4 \mathrm{~N} / \mathrm{mm}$. The Mode-II shear 
damage initiation stresses were therefore taken as per Dai et al (2005) to be $4.9 \mathrm{E}+6 \mathrm{~N} / \mathrm{m}^{2}$ for GFRP. Given the nature of the loading, and the fact that the beam is likely to fail shear, interface failure due to tensile stresses was precluded model by assigning a very large value of the Mode-I normal damage initiation stress. Once shear damage initiates at the interface, damage growth occurs, depending on the work done in causing fracture. This depends on the fracture energy of the interface, which again depends on the grade of concrete and the properties of the laminate. The fracture energy for GFRP was taken to be $14.4 \mathrm{E}+2 \mathrm{~N} / \mathrm{m}$ respectively as per Dai et al. (2005). The interface between the FRP laminate and the epoxy adhesive was modelled as a tied interface. This is because the manner in which the FRP lap is applied - the "wet lay-up" process in which the application of the epoxy and the laying out of the FRP fibres proceeds simultaneously - results in the FRP fibres being encased in an epoxy matrix with no possibility of any significant relative motion between fibres and matrix.

\section{EXPERIMENTAL AND NUMERICAL} RESULTS

\subsection{Crack Pattern and Modes of Failure}

The overall failure characteristics of the experimental beams are included in Table 2. Failure in the S0-0L beam occurred because of the propagation of a single primary shear crack in the shear span accompanied by crack widening: this was possible because of the absence of any shear reinforcement to restrict the crack growth. For ease of discussion, this mode of failure is referred to as a 'Shear III' failure (Table 2). The failure load of the S0-1L beam is $46 \%$ higher than the failure load of the unlaminated S0-0L beam (Table 1). The shear strengthening due to the laminate occurred due to shear stresses acting at the concrete-GFRP interface, thereby limiting crack growth. Once these shear stresses exceeded the bond strength, interfacial debonding commenced and was found to increase with load level. Progressive debonding of the GFRP laminate in the shear spans finally led to beam failure, as shown in Fig. 6. This mode of failure is referred to as 'Shear II' mode, to distinguish it from the 'Shear I' failure observed in the S0-0L beam. On comparing the crack patterns in the S0-1L and S0-0L beams it is seen that, at the same load level, both the width and the length of the web-shear crack is less in the S0-1L beam.

Increasing the number of layers of laminate as in the S0-5L and S0-10L beams delayed crack initiation by increasing the shear resistance. With increase in laminate thickness there was a reduction in the extent of the primary web shear crack and an increase in the extent of cracking at the web flange junction. At higher loads, the junction cracks propagated into the interior of the flange. Some debonding of the GFRP laminate at the junction was observed; however, unlike the S0-1L beam, there was no observable debonding in the web. Beam failure, occurred due to extensive junction cracking rather than FRP debonding. Hence the mode of failure for these beams was significantly different from the S0-1L beam and is classified as 'Shear III' failure.

The crack pattern of the experimental and numerical S0-0L beams are compared in Fig.7. They match perfectly and the failure modes are identical. The crack patterns of the experimental and numerical S0-1L beams are shown in Fig.8. Both beams have the same failure mode and similar crack pattern. Similarly the crack patterns of the experimental S0-5L and numerical S0-1L-5E beams are identical (Fig.9). The crack patterns of the experimental S0$10 \mathrm{~L}$ and numerical S0-1L-10E are seen to be identical as well (Fig.10). Bond damage in the numerical beams is compared in Fig. 11: clearly bond damage in the S0-5L and S0-10L beams is restricted to the junction, unlike the significant bond damage observable in the web of the S0-1L beam.

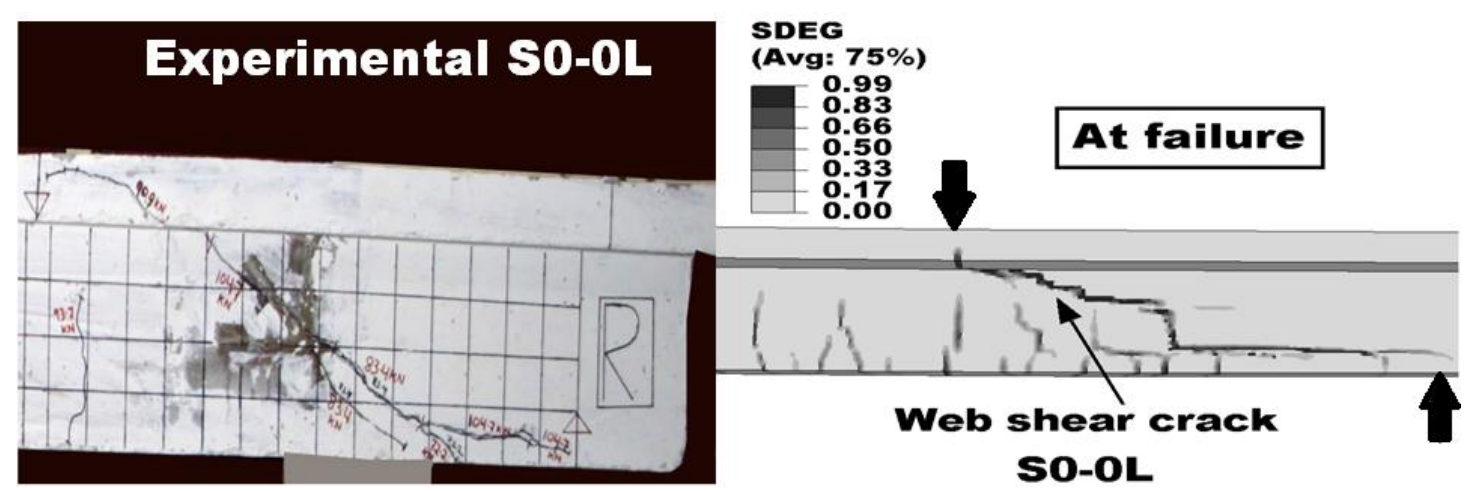

Fig.7. Crack pattern at failure for S0-0L for experimental and numerical beams 


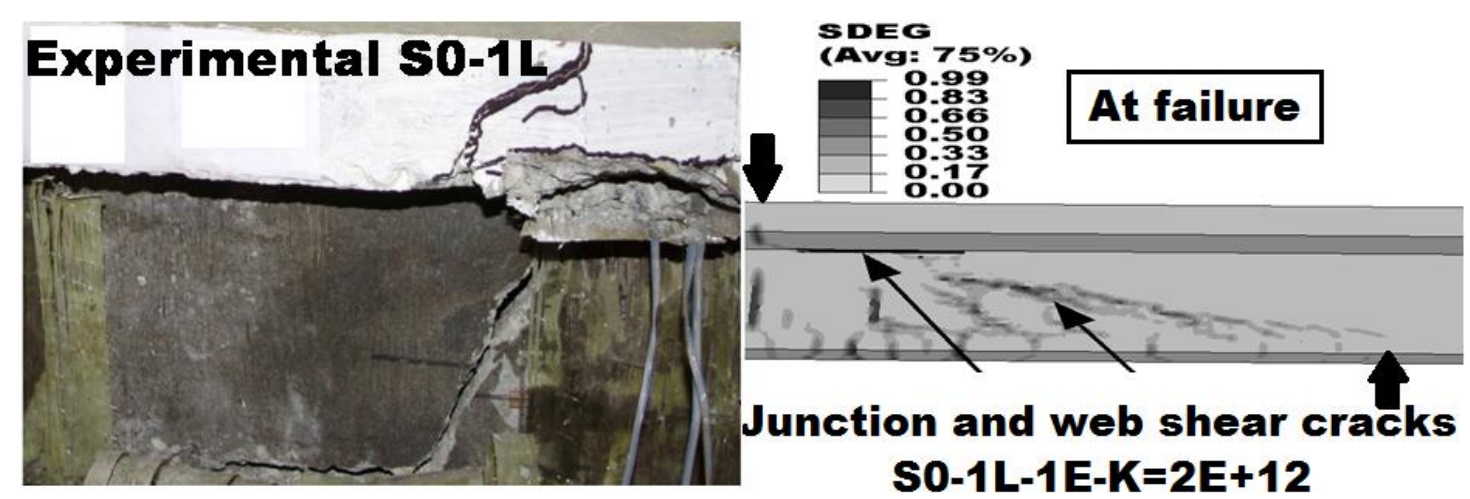

Fig. 8. Crack pattern at failure for S0-1L for experimental and numerical beams
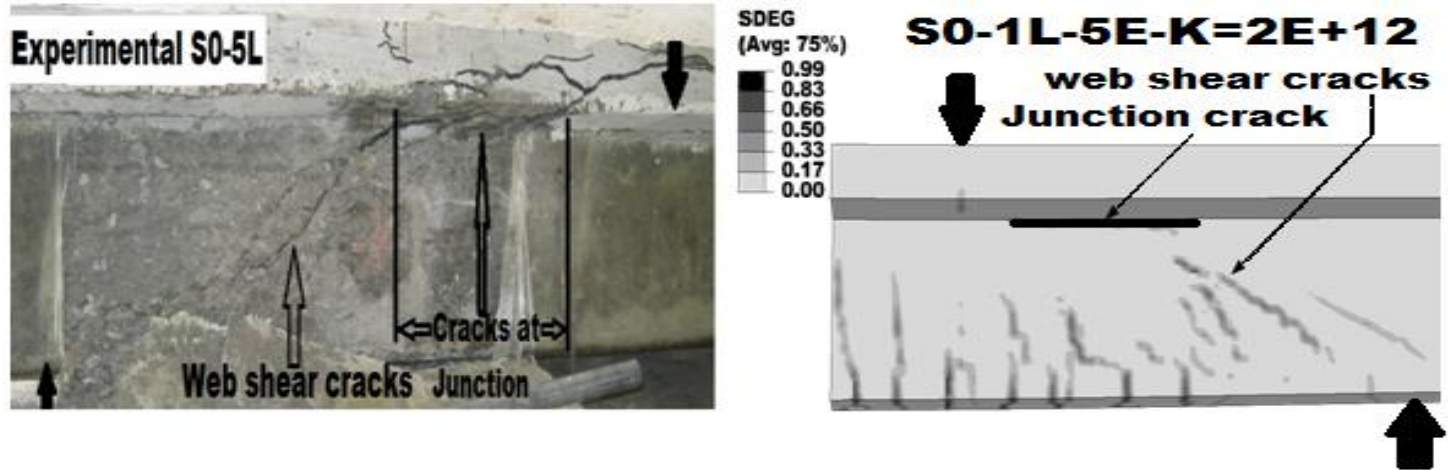

Fig. 9. Crack pattern at failure for S0-5L (E) and S0-1L-5E (N) beam where 'E' stands for experimental beam and ' $N$ ' for numerical beam
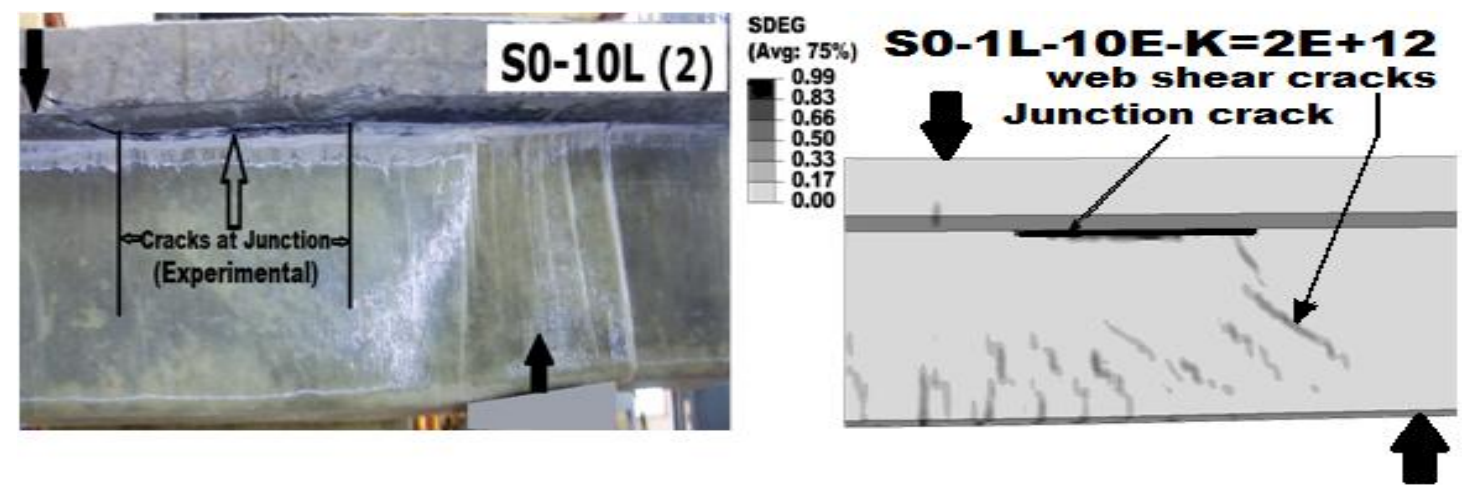

Fig. 10. Crack pattern at failure for S0-10L (E) and S0-1L-10E (N) beams

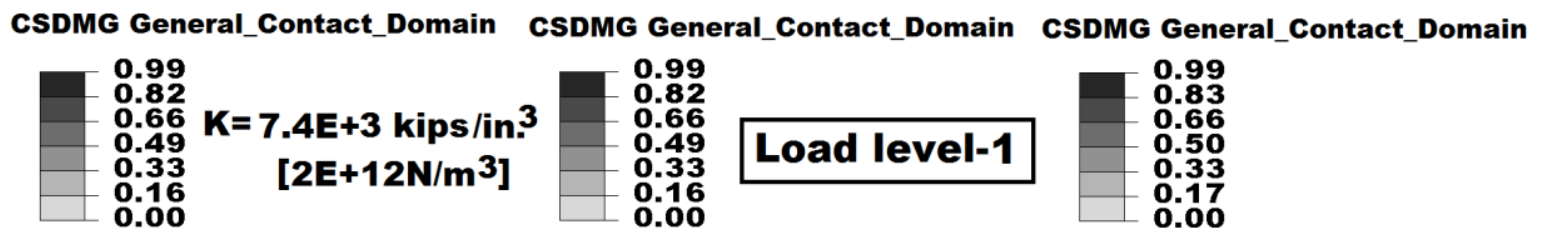

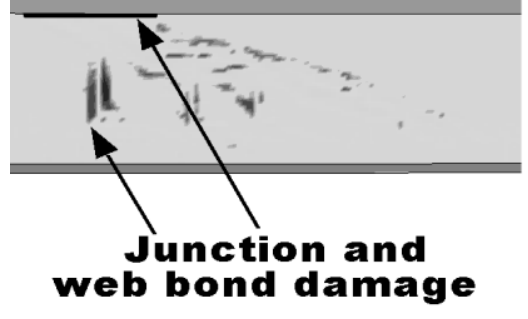

S0-1L

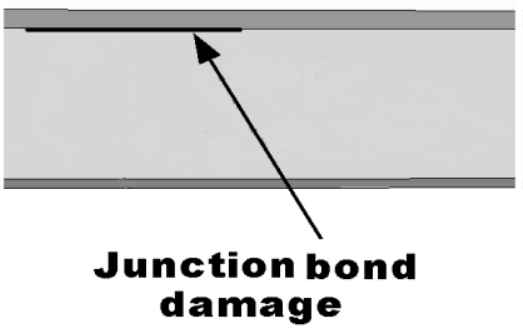

SO-5L

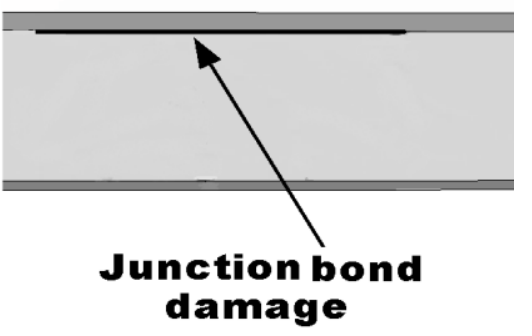

SO-10L

Fig. 11. Comparison of bond damage in web and junction at failure load of S0-10L beam 
The reason for the increase in junction cracking and reduction in bond damage with increase in the value of $K_{\text {laminate }}$ appears to be as follows. Once a shear crack initiates in the web, the GFRP laminate causes shear stresses, aligned along the beam depth, to develop on the web surface. The magnitude of the shear stresses at the web-flange junction increase with laminate modulus. This can be seen from the 1-D analytical model of Yuan et al. (2003) as well, by considering a shear crack located in the web, as shown in Fig. 12, where $L$ is the length of the bond from the webflange junction to the shear crack face in the web, and $x$ is the vertical distance along the bond length. The normalized shear stress $(\tau / P)$ at the web-flange junction can be calculated according to Eqn. (1) and plotted for laminate modulus ranging between the experimentally obtained values for the $1 \mathrm{~L}$ and $10 \mathrm{~L}$ laminates (Fig. 12). It is clear from Fig. 12 that the normalized shear stress at the webflange junction increases while the normalized shear stress at the crack face decreases with laminate stiffness. High shear stresses acting on mutually perpendicular planes at the web-flange junction give rise to principal tensile stresses acting outward at the junction. Once these tensile stresses exceed the tensile strength of concrete, crack growth occurs at the junction. Cracking results in slip, and hence an increase in the magnitude of the bond stresses, which in turn causes bond damage. Once the bond damages, cracking at the junction is unrestrained, and spreads to the interior of the junction. This induces crack growth in the interior of the flange, and eventual beam failure. The simultaneous reduction in the shear stress at the crack face with increase in laminate modulus results in reducing the extent of debonding in the web. This too is consistent with the experimental and numerical results: debonding in the web in the $5 \mathrm{~L}$ and $10 \mathrm{~L}$ beams (with higher $K_{\text {laminate }}$ ) is substantially less than in the $1 \mathrm{~L}$ beam where the $K_{\text {laminate }}$ value is smaller.

\subsection{Failure Loads}

From Table 2, it is observed that as the laminate modulus increases from $1 \mathrm{E}$ to $10 \mathrm{E}$, there is a reduction in load carrying capacity. The failure loads at $5 \mathrm{E}$ and $10 \mathrm{E}$ are $4 \%$ and $9 \%$ less than at 1E. As discussed, the increase in laminate modulus gives rise to two effects. It leads to reduction in concrete damage in the web. It also leads to a sharp increase in shear stresses at the junction of web and flange, resulting in accumulation of concrete damage at the junction. Eventually, the shear stresses in the bond adjacent to the junction cracks exceed bond strength, resulting in bond damage and hence a reduction in the shear contribution of the FRP. The decline in failure load with laminate stiffness clearly shows that the second effect i.e. the effect of junction crack growth is dominating the response at failure. Fig. 13 compares the load-mid span displacement curves. The experimental S0-1L beam has a failure load that is $18 \%$ smaller than the failure load of the corresponding numerical beam. The low gsm of the main (longitudinal) FRP fibers, and the large spacing between the transverse fibers holding the main fibers in place, led to some misalignment of the main fibers in the experimental S0-1L beam. This resulted in reduced strengthening. However, in multi-layer laminates, frictional resistance between the layers limits transverse motion of the main fibers, and thus prevents fiber misalignment. Consequently, experimental and numerical failure loads match closely for the S0-5L and S0-10L beams (Table 2).

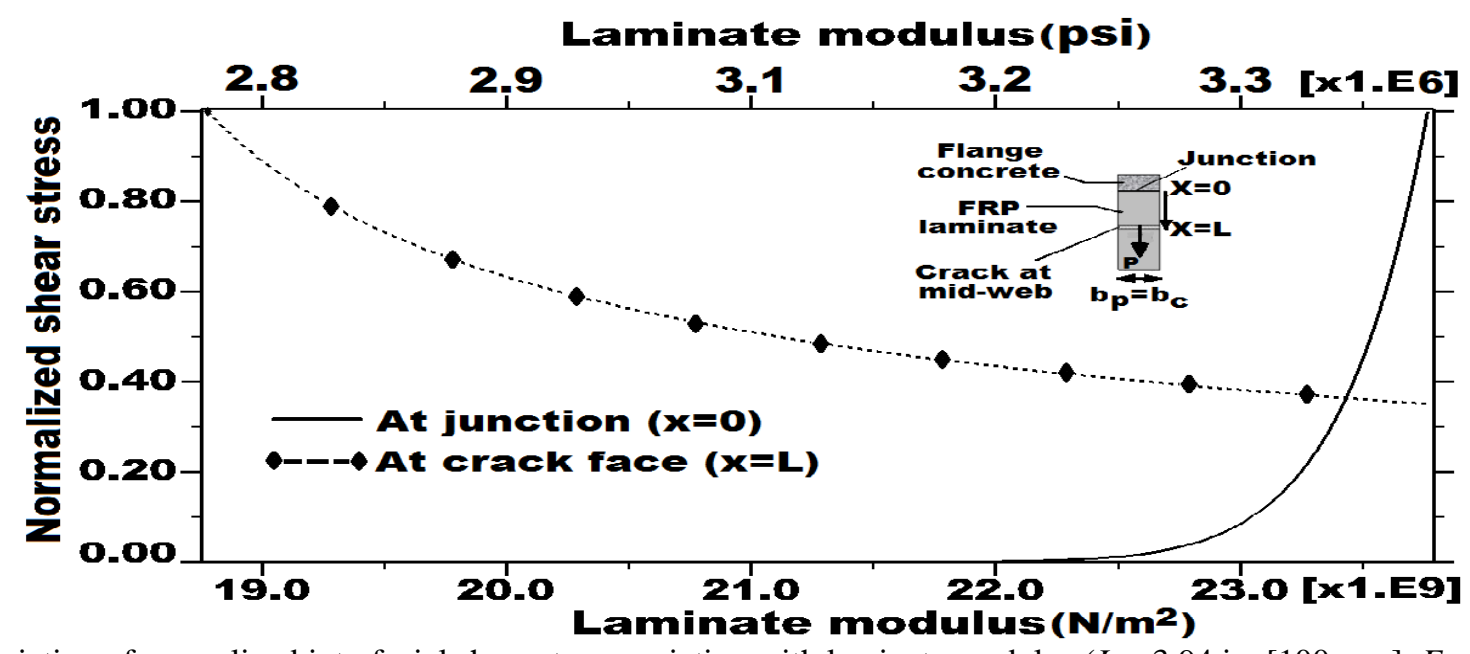

Fig. 12. Variation of normalized interfacial shear stress variation with laminate modulus $\left(L=3.94 \mathrm{in}\right.$. $[100 \mathrm{~mm}], E_{c}=5.5 \mathrm{E}+6 \mathrm{psi}$ $\left[38 . \mathrm{E}+3 \mathrm{~N} / \mathrm{mm}^{2}\right], t_{c}=3.94 \mathrm{in}$. [100 mm], $b_{c}=39.4 \mathrm{in}$. [100 mm], $b_{p}=3.94 \mathrm{in}$. [100 mm], $E_{p}$ and $t_{p}$ vary according to Table 1.$)$ 


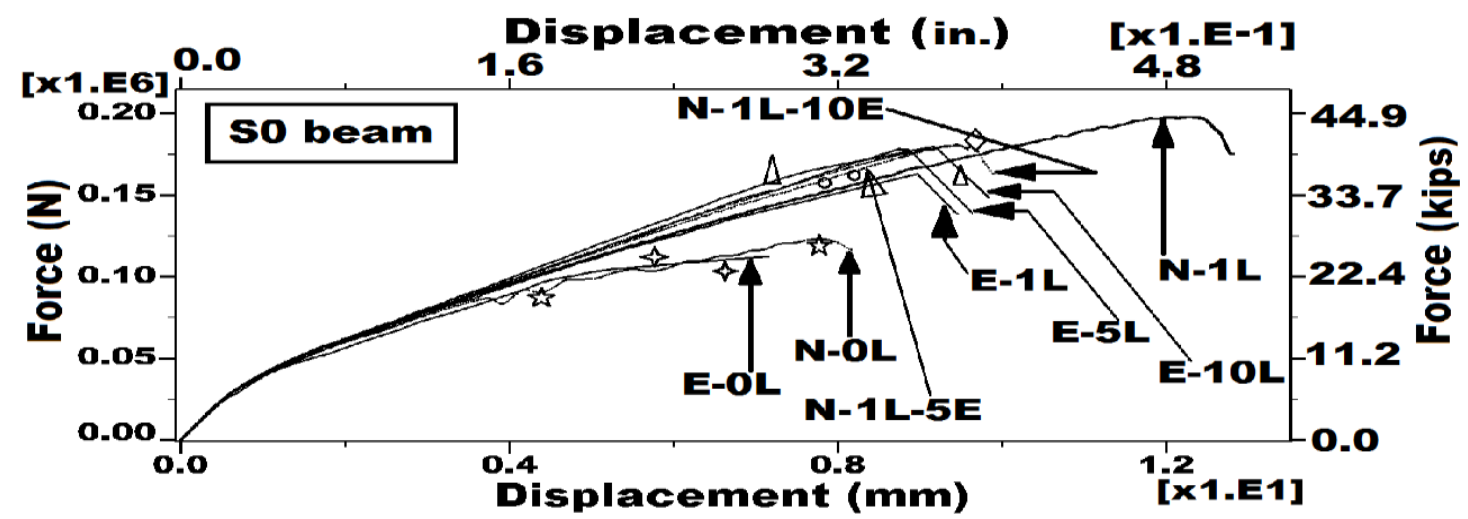

Fig. 13. Experimental and numerical force-displacement curves for SO beams

\subsection{Strains in Steel, Concrete and GFRP}

Strain data was retrieved from finite element locations matching the location of the experimental strain gauges as given in Fig. 2-4, and the numerical and experimental stain histories at these locations were compared. Fig. 14 compares the maximum principal strains in the tensile steel near the support. The strains, at locations shown in Fig. 2, are computed for the numerical beams and compared with the strain gauge readings obtained from the experimental specimens. The strains compare well for all values of laminate modulus. Fig. 15 compares the maximum principal strains in the concrete at mid shear span. The strains, at locations shown in Fig. 3, are computed for the numerical beams and compared with the strain gauge readings obtained from the experimental specimens. The strains compare well for all values of laminate modulus. The strains in the numerical S0-1L beam are somewhat higher because the failure load obtained from the numerical model is $18 \%$ higher. The axial strains in the GFRP at the web-flange junction of the experimental S0-1L, S0-5L and S0-10L beams are compared in order to study the effect of laminate modulus on junction cracking in Fig. 16. The strain in the GFRP laminate at the junction of the S0-10L beam is found to be substantially higher than in the S0-1L beam. It is also apparent that junction distress in the S0-1L beam evolves much more slowly than in the beams with laminates of higher modulus: thus the slope of the axial strain vs. failure load curve is the smallest in the S0-1L beam. The axial strains in the GFRP at the junction of the S0-5L beam are smaller than in the S0-10L beam for load levels of about 165 $\mathrm{kN}$. This is consistent with the occurrence of more strains at the junction in the S0-10L beam. However beyond $165 \mathrm{kN}$, there is a sharp increase in the axial strain in case of the S0$5 \mathrm{~L}$ beam, apparently caused by a rapidly widening junction crack at the location of the strain gauge.

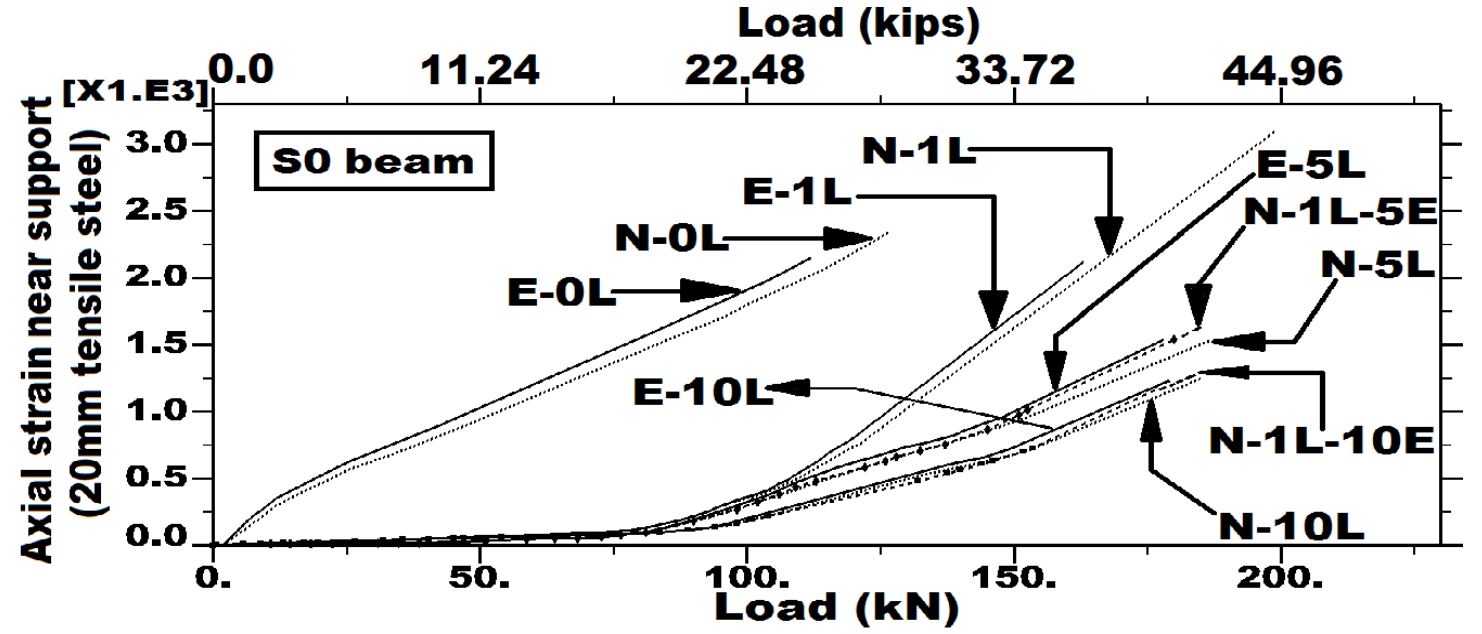

Fig.14. Variation of axial strain in tensile steel with laminate modulus (near support) 


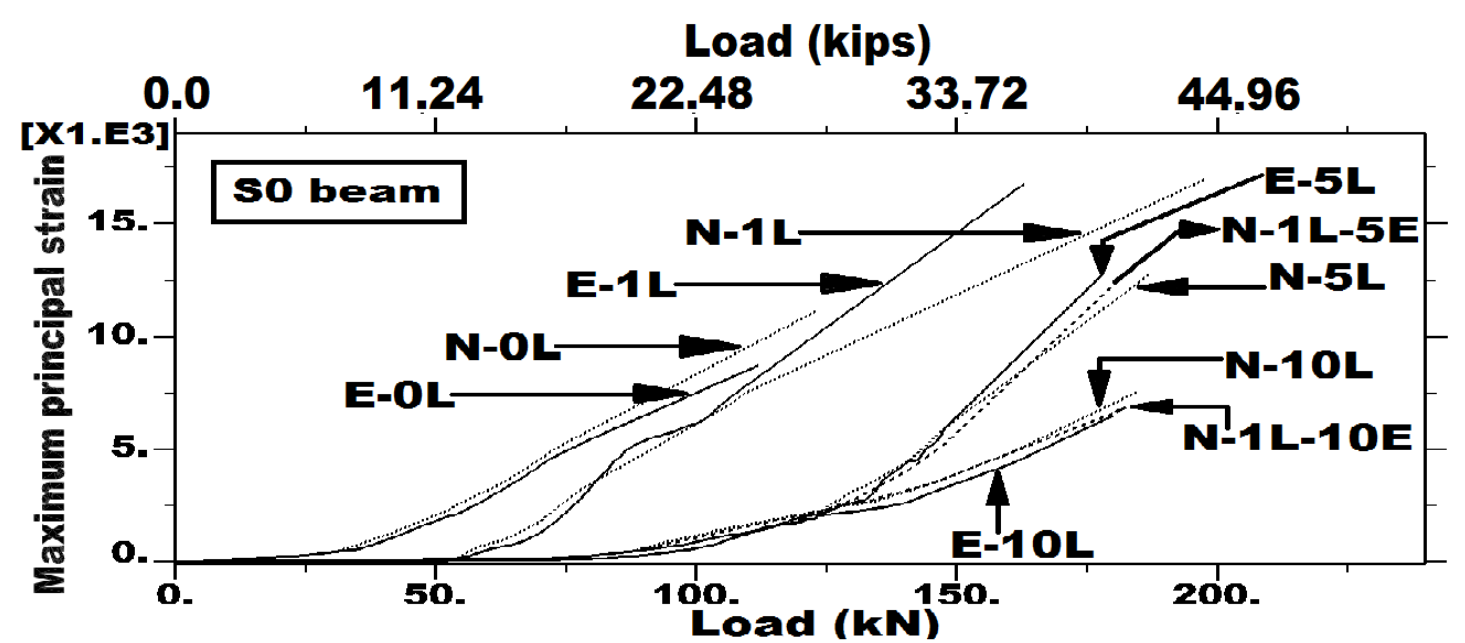

Fig. 15. Variation of maximum principal strain in concrete with laminate modulus at mid shear span

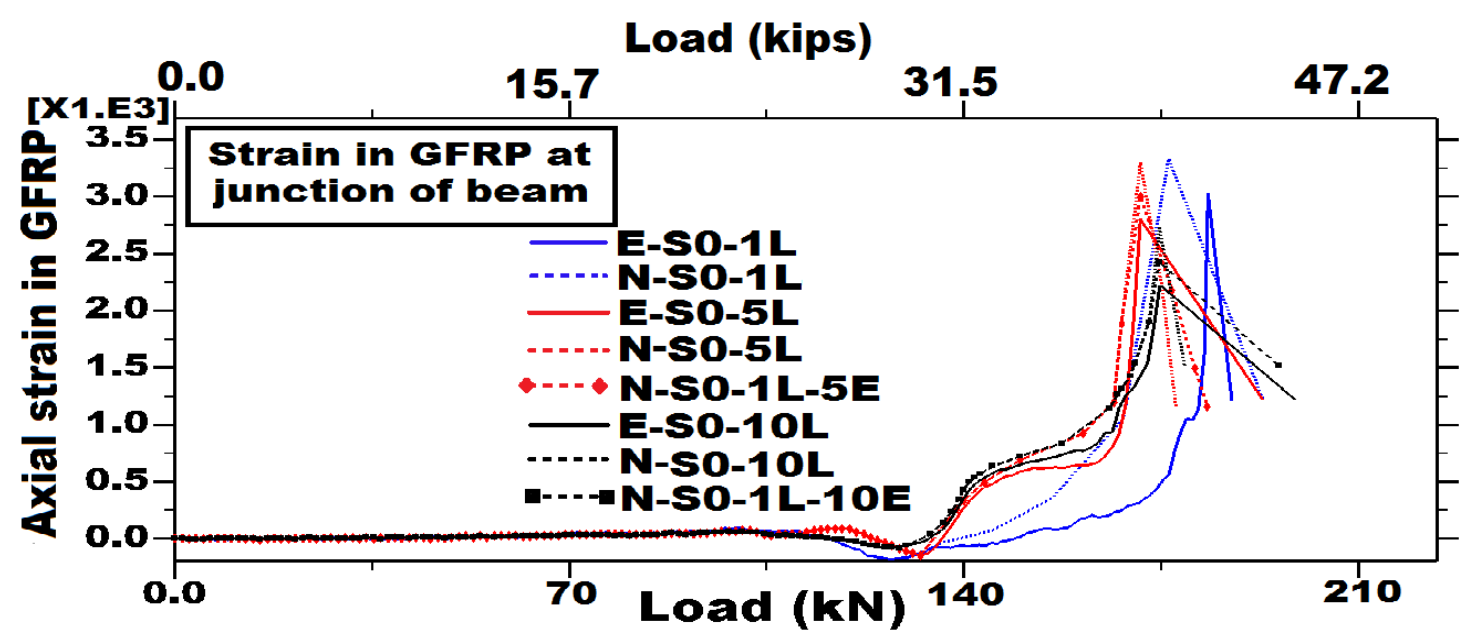

Fig.16. Variation of GFRP strains at junction with laminate thickness

In Figs. 14-16, strain histories obtained from the S0-1L-5E beam are seen to compare well with the strain histories obtained from the experimental and numerical S0-5L beams. Similarly, strain histories from the S0-1L-10E beam match well with the strain histories obtained from the experimental and numerical S0-10L beams.

\section{CONCLUSION}

A FRP laminate can be made stiffer either by increasing laminate thickness or laminate modulus. The overall structural response remains the same if the same if the laminate stiffness values are nearly equal. High values of laminate modulus have decidedly mixed effects. At moderate load levels stiffer laminates reduce web cracking and bond damage in the web. However at higher load levels, stiffer laminates cause a sharp increase in the shear stresses at the web-flange junction. This results in a change in the mode of failure and a reduction in the load carrying capacity. Thus failure in beams with high laminate stiffness is much more likely to be brittle in nature than in beams with moderate values of laminate stiffness.

\section{ACKNOWLEDGEMENTS}

The experiments reported here were performed at the Central Building Research Institute (CBRI), Roorkee. This support is gratefully acknowledged.

\section{REFERENCES}

[1] Abaqus 6.9 (2009). Abaqus User's Manual, Dassault Systemes Simulia Corp., USA

[2] Belarbi, A., Bae, S.W. and Brancaccio, A. (2012), Behaviour of full-scale RC T-beams strengthened in shear with externally bonded FRP sheets, Construction and Building Materials, 32, 27-40.

[3] Bousselham, A., and Chaallal,O. (2006a), Behaviour of RC T beams strengthened in shear with CFRP: an experimental study, ACI Structural Journal, 103(3), 339-347.

[4] Bousselham, A. and Chaallal, O. (2006b), Effect of transverse steel and shear span on the performance of $\mathrm{RC}$ beams strengthened in shear with CFRP, Composites: Part B: Engineering, 37, 37-46.

[5] Chen, J.F. and Teng, J.G. (2003a), Shear capacity of Fiber Reinforced Polymer- Strengthened Reinforced Concrete Beams: Fiber Reinforced Polymer Rupture, Journal of Structural Engineering, 129(5), 615-625. 
[6] Chen, J.F. and Teng, J.G. (2003b), Shear capacity of FRP- Strengthened RC Beams: FRP debonding, Construction and Building Materials, 17(1), 27-41.

[7] Chen, G.M., Teng, J.G. and Chen, J.F. (2013), Shear Strength Model for FRP-Strengthened RC Beams with Adverse FRP-Steel Interaction, Journal of Composites for Construction, 17(1), 50-66.

[8] Dai, J.G. and Ueda, T. (2003), Local bond stress slip relations for FRP sheets concrete interfaces, In: Proc. of 6th international symposium on FRP reinforcement for concrete structures. World Scientific Publications, Singapore, 143-152.

[9] Dai, J., Ueda, T. and Sato, Y. (2005), Development of the Nonlinear Bond Stress -Slip Model of Fiber Reinforced Plastics Sheet-Concrete Interfaces with a Simple Method, Journal of Composites for Construction, 9(1), 52-62.

[10] Eligehausen, R., Popov, E.P. and Bertoro, V.V. (1983), Local bond stress-slip relationship of deformed bars under generalized excitations, Report No. UCBEERC-83/23, Earthquake Engineering Centre, University of California, Berkeley, 169.

[11] Khallifa, A. and Nanni, A. (2000), Improving shear capacity of existing RC T-section beams using CFRP composites, Cement and Concrete Composite, 22 (3), $165-74$.

[12] Khalifa, A. and Nanni, A. (2002), Rehabilitation of rectangular simply supported RC beams with shear deficiencies using CFRP composites, Construction and Building Materials, 16 (1), 135-146.

[13] Lu, X.Z., Teng, J.G., Yea, L.P. and Jianga, J.J. (2005), Bond-slip models for FRP sheets/plates bonded to concrete, Engineering Structures, 27, 920937.

[14] Qiao, P. and Chen, Y. (2008), Cohesive fracture simulation and failure modes of FRP-concrete bonded interfaces, Theoretical and applied fracture mechanics, 49, 213-225.

[15] Ramberg, W., and Osgood, W. R. (1943), Description of stress-strain curves by three parameters, Technical Note No. 902, National Advisory Committee for Aeronautics, Washington DC.

[16] Teng, J.G., Chen, J.F., Smith, S.T. and Lam, L. (2001), Behavior and strength of FRP strengthened RC structures: a state-of-the-art-review, Proceedings of the Institution of Civil Engineers, Structures and Buildings, 156 issue, 51-62.

[17] Teng, J.G., Yuan, H. and Chen, J.F. (2005), FRP-toconcrete interfaces between two adjacent cracks: Theoretical model for debonding failure, International Journal of Solids and Structures, 43, 5750-5778.

[18] Triantafillou, T.C. (1998), Shear strengthening of reinforced concrete beams using epoxy-bonded FRP composites, ACI Struct J, 95(2), 107 -15.

[19] Yuan, H., Teng, J.G., Seracino, R., Wu, Z. S. and Yao, J. (2003), Full-range behavior of FRP-toconcrete bonded joints, Engineering Structures, 26(1), 553-565. 